Original Research Paper

\title{
Willingness to Pay for Water Hyacinth Control in Nepal
}

\author{
${ }^{1}$ Umesh Khatri ${ }^{2}$ Resham Bahadur Thapa-Parajuli and ${ }^{3 *}$ Uttam Paudel \\ ${ }^{1}$ PhD Scholar, Tribhuvan University, Nepal \\ ${ }^{2} \mathrm{PhD}$ Scholar, University of Hull, UK \\ ${ }^{3}$ Environmental Health Economist, Tribhuvan University, Nepal
}

Article history

Received: 31-03-2018

Revised: 06-09-2018

Accepted: 10-11-2018

*Corresponding Author:

Uttam Paudel

Economist, Tribhuvan

University, Nepal

Email: uuupaudel22@gmail.com

\begin{abstract}
Water Hyacinth (WH) has become a growing problem across Asia, specifically in Nepal. Infestations of this weed have reached critical proportions in freshwater bodies, causing environmental, economic, agricultural and social problems. These problems have corresponding monetary values. This study elicits the willingness of visitors and local people to control WH in the Phewa Lake in Nepal. Considering three scenarios encircling different socio-economic variables, we estimated the people's willingness to pay for cleaning WH from the lake. Willingness to Pay (WTP), befitting contingent valuation method, was employed using 13 sample points to capture heterogeneity. We estimated Logit regression coefficients to achieve the elasticity of the demand curve. The findings reveal that the mean WTP for the first scenario, to remove the WH for one year, was NPR 920.51. Similarly, the mean WTP for the second scenario, representing the minimum annual impact, was NPR 717.38 only. Finally, mean WTP for the third scenario that keeps the impact at a low level in the lake for ten years was NPR 1848.17. Based on the preference of beneficiaries and the level of WTP for different scenarios, Nepal government should first prioritize on keeping very low impact of the weed in the lake rather than removing $\mathrm{WH}$ from the lake at once to yields highest possible benefit from the lake. Number of visit, assistance and expenditure are the pertinent factors to offset the WTP of beneficiaries which were significant at $5 \%$ level of significance. Moreover, the estimated demand curve is relatively inelastic meaning that small increase in beneficiary's utility lead to big marginal increase in WTP of visitors and local people.
\end{abstract}

Keywords: Demand Derivation, Logit Regression, Water Hyacinth, Willingness to Pay

\section{Introduction}

The Water hyacinth (Eichhornia crassipes) is an invasive aquatic plant species that causes not only ecological problems, but also economic losses that directly accompany with biodiversity loss (Mironga et al., 2014). Extant studies are devoted only to exploring the ecological damage cost of invasive perennial species control and a handful international studies on $\mathrm{WH}$ have evaluated its ecological damages (Rai and Scarborough, 2013; Pimentel et al., 2005). There is a demonstrated need for economic appraisal of spreading $\mathrm{WH}$ in the lakes near recreational areas. Using the contingent valuation method, the best method for valuing environmental goods, researchers can estimate demand for its control and inform effective ecological conservation policy (Richardson and Loomis, 2009).

Water hyacinth is now extensively grown on multiple continents where tropical and subtropical climates exist
(Foundation and Nagar, 2012). The extensive growth of WH might be due to stationary water bodies and absence of natural enemies. Through positive aspect, WH contributes in producing useful byproducts like animal and fish feed, power plant energy, ethanol, biogas, composting and fiberboard making raw materials (Mbendo and Thomas, 1988). Crucially, a rampant of WH might be a lack of dissolved oxygen due to less light below the water surface, which may lead to the threaten to the aquatic life, creating both an ecological and an economic cost burden.

Water hyacinth was first reported in Western Nepal in 1972 through international trade (McIntosh et al., 2010). Control of this undesirable plant through chemical, physical, biological management strategy seems urgent for the conservation of recreational areas. Though the use of chemical pesticides is one of the plausible solutions, it is still questionable because it might create environmental hazards (Eichhornia et al., 
2011). The variety of bioclimatic zones in Nepal have allowed several foreign species to thrive. However, because most of these foreign species are easily controlled and never out-compete native species, they pose little or no threat to biodiversity, natural ecosystems, or economies (Rezania et al., 2015).

The Forest Act 1995, National Park and Wildlife Conservation Act 1973, Plant Protection Act 2007 and Plant Protection Rules 2010 aim to control invasive species at local and national level. Internationally, Nepal is a signatory to the Convention on Biological Diversity to develop the National Biodiversity Strategy and implementation plan. The International Union for Conservation of Nature (IUCN) and the World Wildlife Fund (WWF) are actively contributing to the controland prevention of invasive species. According to the Nepal Biodiversity Strategy and Action Plan 2014-2020 (GoN/MoFSC, 2014), the invasion of water hyacinth in several internationally important wetlands and lakes, including the Beeshazar Lake in Chitwan District and Phewa Lake in Kaski, is a major threat to the tropical and sub-tropical wetlands. An expert committee has been formed to provide strategic policy guidance for mainstreaming wetland issues into national policy, planning frameworks, as well as ensuring inter-sectoral coordination, cooperation and collaboration.

Water hyacinth in lakes can lead to plummeting tourism revenues from boating and other activities, an increase in malaria incidences and the obstruction of hydropower generation activities. As a result, power interruptions and financial losses act as a barrier to positive economic change (Mbendo and Thomas, 1988). Water hyacinth invasion in Phewa Lake has detrimental effects on tourism, fish habitat and local irrigation systems. Fast-growing WH has long-term impact on the daily livelihood of people who are dependent on the lake and its surrounding businesses. The Phewa environment development committee, Phewa fish entrepreneurs committee and Phewa boat entrepreneurs have worked to clean and remove WH from Phewa Lake with financial help from the tourism board of Nepal. Yet, these activities have mostly been in vain.

An international study has already estimated that infestations of WH cause environmental, economic, agricultural and social problems that can amount to of billions of US dollars (Pimentel et al., 2013). Water hyacinth invasion on Phewa Lake directly affects the riparian communities and all the people who depend on environmental services or production from the affected lake Despite the significant worldwide growth of research on invasive species, there is a paucity of research that is concerned with invasive species valuation in Nepal.

Given the nonexistence of a market for valuing some environmental goods and services, non-market valuation methods are often employed. The two primary methods include revealed preference and stated preference (Nunes and van den Bergh, 2004). Economists have long used two popular revealed preference methods, hedonic price technique and travel cost technique, as proxy concepts that consider the characteristics of environmental goods and recreational costs simultaneously to estimate the actual use value (Navrud and Mungatana, 1994). However, in this particular study, the stated preference method seems suitable tool for exploring social preferences and gauging public support related to invasive plant species control. This method, belonging to the Contingent Valuation Method (CVM), is helpful for directly capturing the WTP of end-users. It is capable of capturing the non-use value or passive value or existence value of environmental goods and services.

This study elicits the non-marketed social value (benefit) of controlling WH from Phewa Lake vis-à-vis the WTP of service users at three intensities of the impact of WH. The study also derives a relatively inelastic demand curve for preserving the environmental goods and services. Many lakes and wetlands in Nepal are recognized worldwide as tourism destinations and as ecological resources that benefit local people and governments. Therefore, the results of a research on the economically engendered social value of clean lake are important for policymakers who are engaged in the management of invasive species.

\section{Methods}

\section{Study Design}

Cross-sectional analytical economic evaluation design was employed using only primary information owing to the absence of secondary data. A stated preference survey was used to assess the economic value of environmental damage due to rampant $\mathrm{WH}$ in the lake. An analytical framework was developed based on a study by McIntosh (2007), assuming the change in maximum utility of service users for different impact levels, possibly posed by WH invasion. Separate WTP of service users for high and low ecological damages by invasion was elicited using a valid hypothetical question. We derived the demand curve, which is relatively inelastic, from the change in WTP for the invasioncontrol period based on population control model (Jaquette, 1972).

\section{Analytical Framework}

The utility concept is the basis for eliciting WTP of service holders for changed ecological scenario and for deriving demand for $\mathrm{WH}$ cleaning in future from the lake. Let $(U)$ be a person's entire lifetime constant utility. It is a combination of good-state $\left(\bar{U}^{0}\right)$ up to invasion time $(\tau)$ and bad-state $\left(\bar{U}^{1}\right)$ from invasion time 
( $\tau)$ to the date of death $(T)$ with the rate of time preference, $\rho$. Then, the utility gained up to $(T)$ becomes the person's entire lifetime utility $(U)$ (Equation 1):

$$
\begin{aligned}
& U=\int_{0}^{\tau} \bar{U}^{0} e^{-\rho t} d t \\
& +\int_{\tau}^{T} \bar{U}^{0}\left[c(t)-\alpha D[x(t)+\tilde{x}(t)], Q^{1}\right] e^{-\rho t} d t
\end{aligned}
$$

Here, $c$ represents consumption at period $t$. $D$ depicts damage function where $\alpha$ acts as the proportion of cost faced by the person. $x$ and $\tilde{x}$ are monetary contributions to invasion control and all other contributions to the invasion control by other parties separately when $Q^{1}$ represents bad state environmental quality. Meanwhile, budget constraint (Equation 2) therefore becomes a simple way to ease mathematical manipulation with full of assumptions as person's wealth $(W)$ with interest rate $r$, consumption choices $c(t)$ and contribution toward lowering ecological damage $x(t)$ :

$$
W=\left[\frac{c(0)}{r}\right] *\left(1-e^{-r \tau}\right)+\int_{\tau}^{T}[c(t)+x(t)] e^{-r t}
$$

The Lagrangian expression, a function of the generalized coordinates, their time derivatives and time and contains the information about the dynamics of the system, of utility maximization within good and bad states of WH covering lake with respect to budget constraint is:

$$
\begin{aligned}
& \underset{c, x}{L}=\int_{\tau}^{T}\left[\bar{U}^{1}\left(c(t)-\alpha D\left(x(t)+\tilde{x}(t), Q^{1}\right)-\bar{U}^{0}\right] e^{-\rho t} d t\right. \\
& +\lambda\left[W-\left[\frac{c(0)}{r}\right] *\left(1-e^{-r \tau}\right)-\left[\int_{\tau}^{T}[c(t)+x(t)] e^{-r t} d t\right]\right]
\end{aligned}
$$

Differentiating Equation (3) concerning $c(t)$ and $x(t)$ and letting $M^{1}=c(t)-\alpha D(x(t)+\tilde{x}(t))$ and $\hat{X}=x+\tilde{x}$ provides the following first-order condition:

$$
\begin{aligned}
& c(t): \bar{U}_{M^{1}}^{1}\left[c(t)-\alpha D(x(t)+\tilde{x}(t)), Q^{1}\right] e^{-\rho t} \\
& +\lambda\left(-e^{-r t}\right)=0 \text { for } \tau \leq t \leq T \\
& x(t):-\alpha \bar{U}_{M^{1}}^{1}\left[c(t)-\alpha D(x(t)+\tilde{x}(t)), Q^{1}\right] D_{\tilde{X}} e^{-\rho t} \\
& -\lambda e^{-r t}=0, D_{\tilde{X}} \leq 0 \text { for } \tau \leq t \leq T
\end{aligned}
$$

Solving Equation (4) and (5) gives:

$$
\lambda=\frac{U_{M^{1}}^{1}\left(1-\alpha D_{\hat{X}}\right) e^{-\rho t}}{2 e^{-r t}}
$$

Ultimately, WTP captures the value of a change in the time of transition from a good to a bad state $(\tau)$. Here indirect utility is $\mathrm{f}(W, \tau)$ holding other parameters at their original position and slope of indifference curve (MRS) as: $-\frac{d W}{d \tau}=\frac{\partial L / \partial \tau}{\partial L / \partial W}$.

Using Envelope Theorem in Equation (3) to determine the WTP value, we get:

$$
\begin{aligned}
& W T P=-\frac{d W}{d \tau}=\frac{\partial L / \partial \tau}{\partial L / \partial W} \\
& -\left[U^{1}\left(c(\tau)-\alpha D\left(x(\tau)+\tilde{x}(\tau), Q^{1}\right)-\bar{U}^{0}\right] e^{-\rho t}\right. \\
& =\frac{+\lambda\left[(-c(0)+c(\tau)+x(\tau)) e^{-r \tau}\right]}{\lambda}
\end{aligned}
$$

Allowing $c(0)=c(\tau)$, keeping $\mathrm{c}$ and $x$ at their optimum level in Equations (4) and (5)] and employing dual optimality condition in (6) exists to simplify all values at $t=\tau$ :

$$
\begin{aligned}
& W T P=\frac{\left[\bar{U}^{0}-\bar{U}^{1}\left(c(\tau)-\alpha D(x(\tau)+\tilde{x}(\tau)), Q^{1}\right] e^{-r t}\right.}{\left[\bar{U}_{M^{1}}^{1}\left(c(\tau)-\alpha D(x(\tau)+\tilde{x}(\tau)), Q^{1} *\left(1-\alpha D_{\tilde{X}}\right)\right] / 2\right.} \\
& +x(\tau) e^{-r \tau}
\end{aligned}
$$

Here, we assumed that $\bar{U}^{0}>\bar{U}^{1}$ and $D_{\bar{X}}<0,(W T P)$ is always non-negative and equal to the difference in utility from the bad to a good state. CVM studies include an estimation of the WTP function that depends on income and other socio-economic characteristics of the respondents to the CVM. Therefore:

$W T P=f(r)$

Here, $r$ stands for the vector of explanatory variables (Scenarios, Income and Socio-economic characteristics). For the simplicity sake, Logit regression model has been employed in this study to obtain econometric model (Equation 9):

$$
\begin{aligned}
& W T P=\alpha 0+\alpha 1 X 1+\alpha 2 X 2+\alpha 3 X 3+\alpha 4 X 4 \\
& +\alpha 5 X 5+\alpha 6 X 6+\alpha 7 X 7+\alpha 8 X 8+e
\end{aligned}
$$

Here:

$X 1=$ Age

$X 2=$ Dependent family member year to clear of $\mathrm{WH}$ for one year

$X 3=$ No of visit

$X 4=$ Expenditure to low impact for one year

$X 5=$ Assistance $\alpha s=$ Coefficients of $X 1$ to $X 8$

$X 6=$ Cost loss $e=$ Error term

$X 7=$ Difference of WTP from low impact for one

$X 8=$ Difference of WTP from low impact for ten year

As per the relevancy of the selected variables, all the variables are described with their expected sign in Table 1. 
Table 1: Description of hypothesized variables

\begin{tabular}{lll}
\hline Variables & Description & Expected sign \\
\hline Age & Age of respondent in years & + \\
Dependent Member & Number of dependent family member those are 0 to 14 and > 60 years old people & - \\
Number of Visit & Number of times household member visit in lake & + \\
Expenditure & Expenditure made by household in Rs annually & - \\
Assistance & $\begin{array}{l}\text { Money received by household in the form of subsidy, help from relatives, temple, } \\
\text { church, NGO and INGO in Rs }\end{array}$ & + \\
Cost loss & Loss due to boat engine damage and enter of WH infield, have to travel further & + \\
& for recreation purpose, etc. is measured in Rs & \pm \\
DelX & Difference of WTP from low impact for one year to clear of WH for one year in Rs & \pm \\
DelY & Difference of WTP from low impact for ten years to low impact for one year in Rs & \pm \\
\hline
\end{tabular}

\section{Study Setting and Design}

Phewa Lake is a natural lake situated in the midst of the metropolitan city of Pokhara in Kaski District. The lake maintains high water levels throughout the year. Since it lies in a low-lying area, the monsoon rainwater from the neighbouring areas is drained into the lake, including several tributary streams such as Harpen. The geographical location of the lake is 28.2154 latitude and 83.9453 longitude. It covers an area of about 5.23 $\mathrm{km}^{2}$, with an approximate water capacity of 43,000,000 cubic meters. The Taal Barahi Temple (a historical pilgrim), Phewa Lake and lake water activities are the main tourist attractions of Pokhara City. The lake's outflow is used to generate electricity and irrigation infrastructure used by local people there are residential settlements and hotels near the north and east banks of the lake, which direct their sewage system directly to the water body. This sewage contributes to the growth of WH. The decision to select Phewa Lake for our study was informed by (i) its status as the most popular tourist destination in Nepal, (ii) its vast biodiversity and (iii) its status as a biodiversity hotspot of ecosystem value.

A semi-structured questionnaire was prepared to assess the WH adverse effects on lake aesthetics, lake biodiversity, human health, economic production, navigation and recreation. KII was taken with the officer of the agriculture office in Pokhara, president of Phewa boat association, secretary of local government and president of the fish farming association in Phewa because they were acutely aware of WH impact. With taking oral consent, the questionnaire was pre-tested with 12 people in different WH control settings before the field survey was finalized. Fieldwork was carried out from $2^{\text {nd }}$ to $9^{\text {th }}$ June 2015 , which is a popular time for visiting Pokhara, as local people join outside tourists in leisure activities. In the beginning, five Key Informant Interviews (KII) were taken to identify perspectives on the negative impact of $\mathrm{WH}$ in the lake and its surroundings. We captured socioeconomic information and WTP of households through in-person interviews. We began the survey at Harpen riverside area and conducted the interviews near the powerhouse area, covering 13 sample points. Our sample captures tourist centers, irrigation canal users group, electricity user groups, boating points, shopping points, vendors, lakeside hotels, the Tal Barahi temple, a morning walk group, fishing locations, swimming places, residential areas and the David falls area.

Based on the design of a survey to elicit a subject's willingness to pay for the control of invasive species damages, we shared the information about invasive species and WH. We informed interview participants that water hyacinth is an invasive species that is not native to Phewa waters and it harms the environment, human health and the economy. Based on the severity of the effect, we classified the impact categories into Low impact and High impact. Then, the participants were introduced to six impact categories: (1) impact on scenic beauty, (2) impact on aquatic life (3) impact on ecosystem health. (4) Economic impact, (5) navigation impact and (6) recreational impact. We informed the respondents about the possibility of the Phewa Lake invasion; the only question is when? We explained to them that an interventional technology exists to get rid of such problem. Appropriate use of such technology can delay the invasion for a given amount of time from today.

The technology for clean-up is not free. We also explained to them that a one-time donation from households within the lake area would be used to form a "trusted public or private environment organization in your region" to be used only for the protection of lake from invasive species. We explained to the households the three pre-tested conditions under which they could consider to make a donation.

\section{Condition 1}

Not yet invaded. A method will keep Phewa lake not invaded (no impacts) for one year. But after one year, non-native species will cause low impacts in a foreseeable future. We assigned a low level of impact for the foreseeable future when there is no adoption of prevention method. 


\section{Condition 2}

Already invaded by non-native species, an intervention method will keep the effects low-impact for one year. However, after one year, high impacts will be for the foreseeable future. We assigned a high level of impact for the foreseeable future, when there is no adoption of prevention method.

\section{Condition 3}

Already invaded by non-native species, but a method will keep the lake at low level impact for ten years. If there is no prevention method chosen, the situation will be a high level of impact for the foreseeable future.

\section{Results}

\section{Descriptive Analysis}

Table 2 depicts the descriptive statistics of major and minor variables via mean, minimum value, the maximum value and standard deviation. Under condition 1, considering low impact after a year, mean WTP for one year to clean the WH was Neplease Rupees (NPR) 920.51. Similarly, mean WTP for condition two, considering the low impact of WH for one year in the lake, was NPR 717.38. Finally, mean WTP for condition 3 , to keep the low lake impact for ten years, was NPR 1848.17. WTP of Service takers seems high for the first scenario in comparison to the second and the third created scenarios. Meanwhile, WTP for the third scenario seems more sensitive.

\section{Econometrics Model}

Willingness to pay, in this particular case, acts as the binary dependent variable while the socioeconomic factors, expenditure (the proxy of income) and other variables stand as independent variables. Logit regression results in Table 3 indicate that among various determinants of WTP, only expenditure, assistance and some visits of the household member to the lake are significant at $5 \%$. Similarly, the number visits and WTP, including household expenditure are positively associated. There are negative significant relationships among any of the assistance available to the households and the WTP. As the age of the respondent increases by one extra year, the odds ratio in favour of WTP for the WH control increases by NPR 0.0180 , other things remaining the same. As one more dependent family member in the respondent households, the odds ratio in favour of WTP for WH control increases by NPR 0.0347 , keeping other variables constant. Ceteris Paribus, as the cost of perceived loss increases by NPR one, the odds ratio in favour of WTP for the WH control is increased by NPR 8.20e-05. The difference of WTP from low impact to remove WH for one year and WTP negatively related to each other at $5 \%$ level of significance. Similarly, the difference of WTP from low impact for ten years to low impact for one year and WTP are positively associated. Moreover, the overall model is fit at $19.40 \%$.

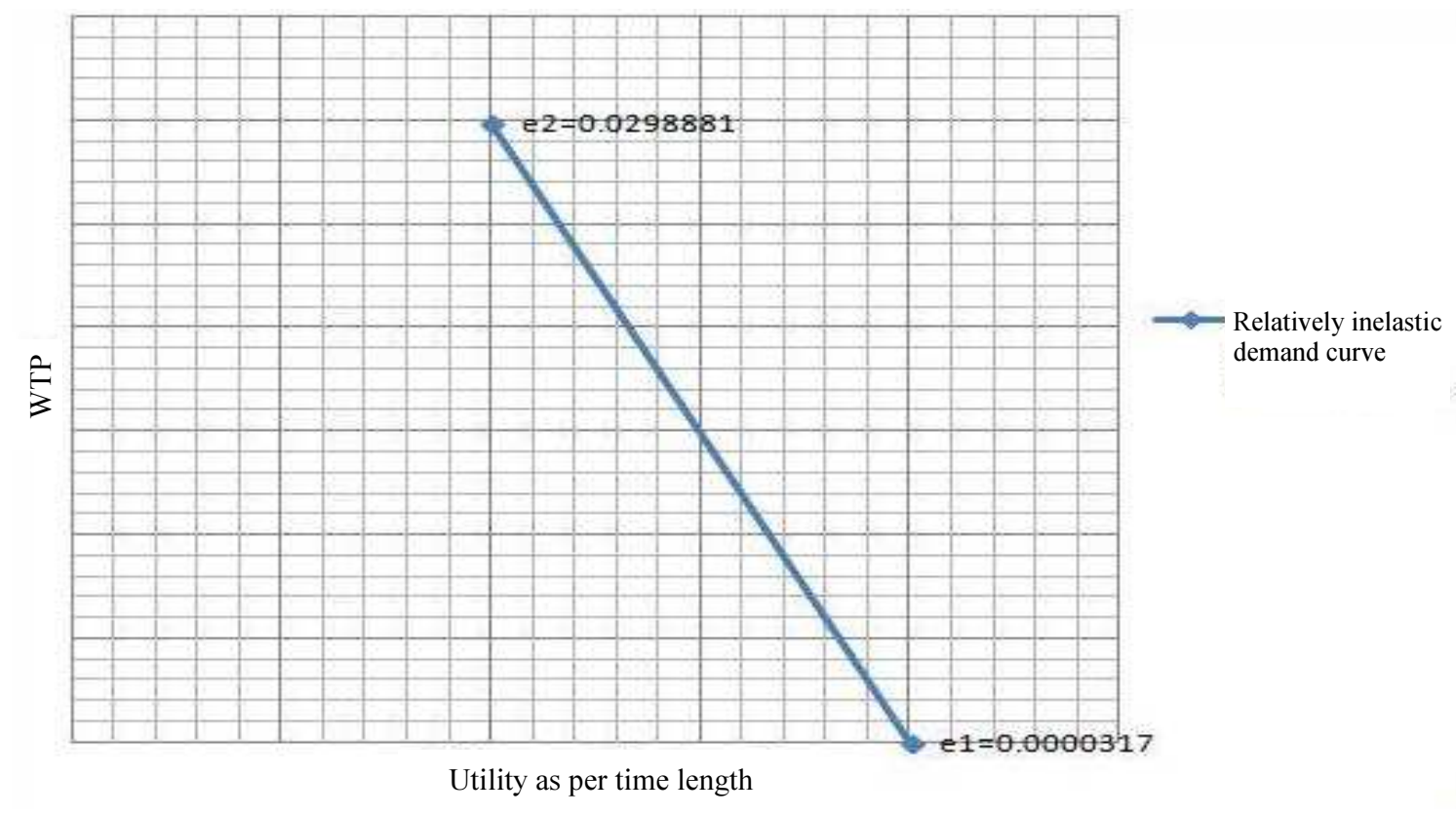

Fig. 1: Demand curve derivation 
Table 2: Descriptive statistics of variables

\begin{tabular}{|c|c|c|c|c|}
\hline Variable & Mean & Minimum & Maximum & Std. Dev. \\
\hline Age & 34.93 & 17.00 & 63.00 & 11.41 \\
\hline Assistance & 475.25 & 0.00 & 6000.00 & 1628.46 \\
\hline Benefit_Dummy & 0.91 & 0.00 & 1.00 & 0.28 \\
\hline Boating_Swimmimg & 3.04 & 1.00 & 5.00 & 1.39 \\
\hline Cost_loss_Dummy & 0.18 & 0.00 & 1.00 & 0.38 \\
\hline Cost_lossin_Rs & 4938.42 & 0.00 & 246000.00 & 30185.00 \\
\hline Economics_College & 1.67 & 1.00 & 3.00 & 0.49 \\
\hline Education & 2.64 & 1.00 & 6.00 & 1.67 \\
\hline Employment & 3.49 & 1.00 & 9.00 & 1.83 \\
\hline Enjoying_nature & 4.20 & 1.00 & 5.00 & 1.02 \\
\hline Env_College & 1.78 & 1.00 & 3.00 & 0.44 \\
\hline Expenditure & 324238.00 & 60000.0 & 1300000.0 & 199773.0 \\
\hline Fishing_Hunting & 2.24 & 1.00 & 5.00 & 1.33 \\
\hline Gender_Dummy & 0.84 & 0.00 & 1.00 & 0.37 \\
\hline Harm_to_Economy & 3.96 & 1.00 & 6.00 & 1.51 \\
\hline Harm_to_Health & 3.08 & 1.00 & 6.00 & 1.39 \\
\hline Harm_to_Lake & 4.55 & 1.00 & 6.00 & 0.94 \\
\hline Income & 3.56 & 1.00 & 6.00 & 1.66 \\
\hline Language & 1.08 & 1.00 & 3.00 & 0.37 \\
\hline Martial_Status & 1.29 & 1.00 & 5.00 & 0.57 \\
\hline Org_Mēmber & 1.82 & 1.00 & 3.00 & 0.43 \\
\hline $\mathrm{WTP}$ & 0.89 & 0.00 & 1.00 & 0.31 \\
\hline Picnic & 1.82 & 1.00 & 4.00 & 0.79 \\
\hline Praying & 2.96 & 1.00 & 5.00 & 1.09 \\
\hline TV & 1.14 & 1.00 & 3.00 & 0.37 \\
\hline No_of_Visit & 1.81 & 1.00 & 2.00 & 0.39 \\
\hline WH_G_Knowledge & 2.61 & 1.00 & 3.00 & 0.55 \\
\hline WH_P_Knowledge & 2.13 & 1.00 & 3.00 & 0.81 \\
\hline WH_Notice_Dummy & 0.99 & 0.00 & 1.00 & 0.099 \\
\hline WH_Problem_Dummy & 0.94 & 0.00 & 1.00 & 0.24 \\
\hline WT"̄1 & 920.51 & 0.00 & 5000.00 & 1236.06 \\
\hline WTP2 & 717.38 & 0.00 & 5000.00 & 877.39 \\
\hline WTP3 & 1848.17 & 0.00 & 12000.00 & 2569.86 \\
\hline Walking & 2.98 & 1.00 & 5.00 & 1.53 \\
\hline Age_group & 5.24 & 3.00 & 7.00 & 0.84 \\
\hline Caste & 1.46 & 1.00 & 3.00 & 0.71 \\
\hline Dep_Family_Mem & 1.45 & 0.00 & 5.00 & 1.20 \\
\hline Indep_Family_Mem & 2.77 & 1.00 & 6.00 & 1.04 \\
\hline Property_Dummy & 0.18 & 0.00 & 1.00 & 0.38 \\
\hline
\end{tabular}

Table 3: Results of logit regression, dependent variable: WTP

\begin{tabular}{ll}
\hline Independent variable & Coefficient \\
\hline Age & 0.0180 \\
& $(0.0371)$ \\
Dep_Family_Member & 0.0347 \\
No_of_Visit & $(0.315)$ \\
& $1.561^{* * *}$ \\
Expenditure & $(0.814)$ \\
& $-340 \mathrm{e}-06^{* * *}$ \\
Assistance & $(1.75 \mathrm{e}-06)$ \\
& $-0.000325^{* * *}$ \\
Cost_Loss_Rs & $(0.000173)$ \\
& $8.20 \mathrm{e}-05$ \\
DelX & $(0.000252)$ \\
& $-6.41 \mathrm{e}-05$ \\
DelY & $(0.000387)$ \\
& 0.000370 \\
Constant & $(0.000295)$ \\
Observations & 1.466 \\
Pseudo R2 & $(1.523)$ \\
\hline Standard errors in parentheses; $* * * \mathrm{p}<0.01, * * \mathrm{p}<0.05, * \mathrm{p}<0.1$ & 101 \\
\end{tabular}

\section{Derivation of Demand through Elasticity of WTP}

Different elasticity of econometrics model extracting elasticity of WTP (e1) with moving from the first to the second condition mentioned below is 0.0000317 and elasticity of WTP (e2) for second and third conditions are 0.0298881 . The negatively sloped demand curve, as shown in Fig. 1, is relatively inelastic.

\section{Discussion}

Before the above results are discussed, we will first discuss study error. First, this study does not cover WTP of all consumers, both local and non-local, who enjoy the services provided by Phewa Lake. First, many people who consume ecological services from Phewa Lake live elsewhere, including Kathmandu and foreign countries. Not all societal benefits can be estimated regarding market prices and not all ecological data are available in 
the context of Nepal. Second, this study did not cover the estimation of institutional household benefits, which may be significant for calculation of total welfare gained from the lake comely. Furthermore, the paper did not include many costs and externalities pertaining to the control of invasion of WH. If this information was available, the net societal benefit would be significant for influencing attitudes towards the control of WH invasion. This study is limited only to the information on a single lake. Therefore, this analysis delivers a truncated view of the real implementation of the controlling measures.

In spite of some pitfalls associated with ecological departments and other exogenous social and environmental factors shaping interventions in the control of $\mathrm{WH}$ in the lake, the analytical and systematic procedure in this research seems a reasonable method for eliciting WTP of beneficiaries in different scenarios. The extraction of economic value of ecological damages and possible interventions within a poorly-informed community is a challenging task. The paper has contributed to the literature by providing methods for the estimation of WTP originating from ecological services as well as demand for the control of inevitable invasion.

Despite the given assumptions and the exclusion of non-quantifiable benefits, $\mathrm{WH}$ is a potential candidate for control at this moment. Interestingly, mean WTP for WH for given conditional interventions is lower than those reported in a study on Mikania micrantha mitigation (Pimentel et al., 2005) and on invasive species (McIntosh et al., 2010). However, this result is almost similar to a study conducted in Netherland (Nunes and van den Bergh, 2004).

Regression results showed that household expenditures, assistance received and the occassional visitors of the lake are significant while the other explanatory variables are insignificant. The major determinants of WTP mentioned above in the result are similar to the findings from a study of invasive species in the United States (McIntosh et al., 2010). Thus, the successful implementation of the interventions in the control of WH in Phewa lake can concoct gigantic benefits to the stakeholders linked with Phewa lakeusers. There is a growing consensus among concerned agencies and policymakers that new supporting institutions and policies are needed to capture the full benefits of the lake and minimize the associated risks (García-Llorente et al. 2011; Knowler and Barbier, 2005).

The argument for investment to control WH becomes stronger when other economic benefits such as poverty reduction, improvement to the economic welfare and better household economy are considered (Lovell and Stone, 2005). Furthermore, the results show that a considerable amount of money is required for maintaining the original view of the lake without any invasion and inelastic demand of the society. Therefore, it requires Cost Benefit Analysis to reset the targeted level of benefits from the lake through rousing motivation to the local people, government and environmentalists working for ecosystem balance in the design of policy for getting more benefits within the given level of costs.

Besides, invasive plants enter Nepal from other regions and countries, the government should establish a large trans-boundary checkpoint to aid in the control of invasive plants (Knowler and Barbier, 2005; Shogren and Tschirhart, 2005; Hester et al., 2004). Similarly, effective trans-boundary check and immediate intervention program based on the result of this research can make the lake free form $\mathrm{WH}$, which can be the potential information story for other international weed control program makers. All in all, this timely information regarding societal demand for the control of weed invasion over wetlands should be a necessary and prioritizing task of each government of affected countries all over the world.

\section{Conclusion}

This paper has developed a framework to estimate the benefit for WH curbing based on welfare theory. We used economic valuation techniques to capture the benefits of aquatic invasive species removal, initiating with utility concept. Results are achieved through the development of an analytical framework and an empirical econometric model to derive a testable hypothesis over the value of ignoring impacts of WH invasion. More notably, we found that a mean WTP for delaying low impacts for one year is quite higher than for delaying high impacts for one year and is almost half for delaying large consequences for ten years per household. Household expenditures, assistance received and occassional presence of a household member who has visited the lake are significant factors. Further, derivation of elasticity demand curve finally explains that WTP of beneficiaries is highly sensitive with utility of lake, meaning that beneficiaries are ready to contribute for any program related to Lake free from $\mathrm{WH}$.

\section{Acknowledgement}

Authors especially acknowledge Shae Frydenlund (sfrydenlund1@gmail.com) for valuable suggestions and comments. Besides, the authors also acknowledge comments and suggestions from faculty members of Tribhuvan University and University Grant Comission Nepal.

\section{Author's Contributions}

Umesh Khatri and Uttam Paudel prepared the manuscript and Resham Bahadur Thapa-Parajuli added inputs in the manuscript. Finally, all the authors approved the final form of the manuscript. 


\section{Ethics}

Ethical issues were clearly addressed orally while collecting information and till the completion of research.

\section{References}

Eichhornia, H., C. Mart and S, Lake, 2011. Biological and chemical assessment of water.

Foundation, A. and K. Nagar, 2012. A review on water hyacinth (Eichhornia crassipes) and phytoremediation to treat aqua pollution in velachery lake, chennai - tamilnadum. Jaikumar. Int. J. Recent Sci. Res., 3: 95-102.

García-Llorente, M., B. Martín-López, P.A. Nunes, J.A. González and P. Alcorlo et al., 2011. Analyzing the social factors that influence willingness to pay for invasive alien species management under two different strategies: Eradication and prevention. Environ. Manage., 48: 418-435. DOI: $10.1007 / \mathrm{s} 00267-011-9646-\mathrm{z}$

GoN/MoFSC, 2014. National biodiversity strategy and action plan 2014-2020.

Hester, S.M., D.I.S. Odom, O.J. Cacho and J.A. Sinden, 2004. Eradication of exotic weeds in Australia: Comparing effort and expenditure. University of New England.

Jaquette, D.L., 1972. A discrete time population control model. Math. Biosci., 15: 231-352.

Knowler, D. and E. Barbier, 2005. Importing exotic plants and the risk of invasion: Are market-based instruments adequate? Ecol. Econ., 52: 341-354.

Lovell, S.J. and S.F. Stone, 2005. The economic impacts of aquatic invasive species: A review of the literature. NCEE Working Paper Series.

Mbendo, J. and T.H. Thomas, 1988. Development technology working Paper No. 51 economic utilisation of water hyacinth from lake victoria.

McIntosh, C.R., J.F. Shogren and D.C. Finnoff, 2010. Invasive species and delaying the inevitable: Valuation evidence from a national survey. Ecol. Econ., 69: 632-640.

McIntosh, C.R., J.F. Shogren and D.C. Finnoff, 2007. Invasive species and delaying the inevitable: Results from a pilot valuation experiments. Agriculture and Applied economics, 39:83-95
Mironga, J.M., J.M. Mathooko and S.M. Onywere, 2014. Effects of spreading patterns of water hyacinth (Eichhornia crassipes) on zooplankton population in lake Naivasha, Kenya. Int. J. Dev. Sustain., 3: 1971-1987.

Navrud, S.Å. and E.D. Mungatana, 1994. Environmental valuation in developing countries: The recreational value of wildlife viewing. Ecol. Econ., 11: 135-151.

Nunes, P.A.L.D. and J.C.J.M. van den Bergh, 2004. Can people value protection against invasive marine species? Evidence from a joint TC-CV survey in The Netherlands. Environ. Resour. Econ., 28: 517-532. DOI: 10.1023/B:EARE.0000036777.83060.b6

Pimentel, D., L. Lach, R. Zuniga and D. Morrison, 2013. Environmental and economic costs associated with non-indigenous species in the United States. J. Chem. Inf. Model., 53: 1689-1699.

Pimentel, D., R. Zuniga and D. Morrison, 2005. Update on the environmental and economic costs associated with alien-invasive species in the United States. Ecol. Econ., 52: 273-288.

Rai, R.K. and H. Scarborough, 2013. Economic value of mitigation of plant invaders in a subsistence economy: Incorporating labour as a mode of payment. Environ. Dev. Econ., 18: 225-244.

Rezania, S., M. Ponraj, A. Talaiekhozani, S.E. Mohamad and M.F. Md Din et al., 2015. Perspectives of phytoremediation using water hyacinth for removal of heavy metals, organic and inorganic pollutants in wastewater. J. Environ. Manage., 163: 125-133. DOI: $10.1016 /$ j.jenvman.2015.08.018

Richardson, L. and J. Loomis, 2009. The total economic value of threatened, endangered and rare species: An updated meta-analysis. Ecol. Econ., 68: 1535-1548. DOI: $10.1016 /$ j.ecolecon.2008.10.016

Shogren, J.F. and J. Tschirhart, 2005. Integrating ecology and economics to address bioinvasions. Ecol. Econ., 52: 267-271. 